\title{
Institutional Logics and Digital Collective Action at Amnesty International - the Decoder Initiative
}

\author{
Lisen Selander \\ Swedish Center for Digital Innovation, \\ Department of Applied IT, \\ University of Gothenburg. \\ lisen.selander@ait.gu.se
}

\author{
Sirkka L. Jarvenpaa \\ Center for Business, Technology and Law, \\ McCombs School of Business, \\ The University of Texas at Austin. \\ Sirkka.Jarvenpaa@mccombs.utexas.edu
}

\begin{abstract}
As social movement organizations (SMOs) enter the platform economy to transform their processes and scale their impact, they have to reckon their traditional logic with the emerging logic of the platform organization. In this paper we examine the Decoder initiative at Amnesty International. The Decoder initiative introduced the global SMO into the uncharted territory of online microtasking of political activism. The platform allowed rapid scaling of repetitive unstructured data tasks to generate large quantities of standardized data, leveraging the work of thousands previously unaffiliated digital supporters around the world. While partially contrasting, we trace and examine the coexistence of the SMO and digital platform logics. We conclude with implications for theory and practice.
\end{abstract}

\section{Introduction}

Enabled by information technology, the digital platform economy is reshaping political action work just as it is transforming business models, new ways of working, and identities in business organizations and the broader economy [1,2]. Global and widespread political movements such as women's empowerment movements \#MeToo and Time's Up leveraged public social media platforms and scaled through the informal networks and new ways of mobilizing millions of digital supporters. Essentially these movements not only crossed organizational boundaries, nations, and technologies $[3,4,5,6]$, but they also leveraged digital platforms to innovate new repertoires that allowed previously unaffiliated digital supporters to engage in collective action. We refer to "digital scaling" as the development and use of digital platforms to attract new groups of actors for political action work. Such scaling does not only require new platform infrastructures but also new organizing processes and logics [1].

Digital platforms promise scale and dissemination of political action work through low-in and out barriers for action and engagement [6]. The platforms accommodate a broad and heterogeneous crowd of activists with multiple agendas and often low stakes through "microtasks". Activists can, for example, engage in a single issue without the boundaries of a formal organization [7, 8, 9]. In this way, digital activists can be entrepreneurial and maintain their independence and autonomy.

The individual autonomy, diverse goals, multiple issues, weak-tie engagement and heterogeneity that comes with digital scaling contests the logic of traditional SMOs. As Klandermans [10 p.234 $]$ suggested, SMOs "...play a significant role in the process of construction and reconstruction of collective beliefs and in the transformation of individual discontent into collective action." SMOs are complex goal-oriented organizations that manifest themselves through authoritative bureaucratic features such as rigid control structures and clear roles [11]. Furthermore, SMOs are dependent on large scale strongly-tied networks and deeply held values (collective identity) towards the movement goals [12]. Essentially SMOs are designed to leverage political and structural change by mobilizing and directing the actions of a cohesive collective, build alliances, and push resources towards a single shared goal.

Yet, SMOs increasingly experiment with digital platforms for digital scaling. For example, Save the Children experimented with Augmented Reality Projects aimed to bring to life the true experiences of political conflict, injustices, violence and war. While promising in reach and range, such experiments are small scale initiatives and little is known about the successes and challenges that come from introducing the new platform logic to the SMO and how it is reckoned with the existing logic. Hence, our research 
question is: how does a digital platform logic for collective action coexist with an existing SMO logic?

In this paper, we follow the journey of Amnesty Internationals "Decoder" initiative in which digital supporters were invited to contribute to Amnesty's research. The digital platform leveraged microtasking for political action. This included, for example, validation of satellite data images to track down potential human rights violations in Darfur. The decoder initiative followed a platform logic, in which heterogenous actors took (isolated) individual action on the behalf of Amnesty. This was very different from the pre-existing SMO logic found at Amnesty. While we found little evidence of logic synthesis [13], we found how the logics co-existed, and fertilized each other through partial blending.

\section{Digital Platforms and Institutional Logics}

By digital platforms, we refer to "...sociotechnical assemblage encompassing technical elements (of software and hardware) and associated organizational processes and standards" that mediate between different user groups that can be either external or internal to the platform provider [14]. Digital platforms are associated with entrepreneurial action, digital scaling, and distributive governance under the guidelines and policies of the platform provider [15, 16].

Much research already speaks to the role of digital technologies in fundamentally changing the structure, expressions, and dissemination of contemporary collective action at the movement level $[7,8,17,18$, 19 , 20]. Such research has helped to advance theoretical and empirical understanding on how digital platforms coordinate actions of heterogeneous and autonomous groups of activists, and in coproducing and disseminating political and social dissent.

What is less well understood is the impact of digital platforms and digital scaling to the logic operating inside incumbent social movement organizations (SMOs) that enter the platform economy. SMOs have historically played a central role in the societies to challenge public policies, injustices and socio-economic institutions. Still, SMOs are put under increased pressures to show social impact and scale [11] and digital platforms appear to be just the solution to the pressures of SMOs. But as value-based, organizations, SMOs are tightly governed by their long-standing logic of collective identity, tight control and coordinated action.

Logics are generally viewed as organizing principles that embody goals, belief systems, and expectations that guide legitimate behavior in institutions [21, 22]. Institutions are organized and established with their historical roots, processes, and identities. Logics provide stability and consistency in these institutions particularly as they operate in dynamic environments facing pressures and heterogeneous stakeholder expectations [23]. In voluntary organizations where there is much turnover and change in supporters, logics reduce tension, increase attention, consensus and conformity to norms and rules. Institutional logics, in this way, shape the attention, expectation and interpretation of meaning. Logics can change and new logics can form either in a top-down fashion or through bottom up interactions and communications [23].

Hybrid organizations are organizations that incorporate elements form multiple institutional logics $[21,22,24]$. Logics can be decoupled if one logic is endorsed more and allowed to dominate, but hybridity can also be maintained through compromising. Compromising involves costly negotiations to balance the competing and contrasting logics. One alternative to avoiding costly negotiations is blending; blending allows both belief systems to coexist and benefit each other through collaborative relationships [25, 26]. Conflict and fragmentation can be avoided as long as there is respect and legitimacy for both logics [27]. Another strategy to tackle competing logics is through selective coupling. For example, Pache and Santos [25] illustrate how social enterprises that "were caught between competing demands of market logic and social welfare logic", engaged in selective coupling in order to build legitimacy and sustain over time. They found that organizational actors combined and borrowed a minimal set of behaviors from both logics in order to please their social and commercial constituencies. In another study Qiu et al. [13] examined two logics of independent app developers on the iOS platform: the logic of profession and the logic of market. The researchers found that although the app developers may have initially leaned toward one of the logics, they compromised and revised their processes to accommodate elements of the opposing logic to create what the authors referred to as "logic synthesis" moderated by the platform provider's guidelines and user interactions.

We know little about how such logic synthesis, decoupling, compromising, or blending might take place in a SMO entering a platform economy. Much is likely to depend on the type and configuration of the digital platform. Microtasking platforms allow entrepreneurial action but within narrow domains and the confines of the well-established policies and guidelines set up by the platform provider [28, 29]. Microtasking platforms aggregate hundreds and thousands of repetitive microtasks performed by 
independent workers. Even when tasks have unstructured input but produce standardized output, the platform can dramatically reduce cost and time to complete the work that may have previously been conducted by employees [28].

\section{Method}

\subsection{Case Context}

Amnesty International (Amnesty) is a human rights organization with more than 7 million members and supporters globally. The Decoder initiative was initiated in late 2014 when the Swedish section of Amnesty received 1,2 million USD funding from the Swedish postcode lottery, (http://www.postkodstiftelsen.se/en/) to initiate the project. The funding for the project was somewhat unexpected: "It was a bit of a lucky strike, this was the first time that the external funder accepted that funding could be situated outside of Sweden." (Swedish Amnesty representative, 2015). To meet the criteria for innovation, the proposal had elements of micro-tasks and crowd work. The Amnesty representatives working on the proposal had been inspired by other human rights organization's initiatives; "I was super inspired by Avaaz and the things they were doing... I just thought that we would be able to do whatever they do." (Swedish Amnesty representative, 2015).

The funding was transferred to the International Secretariat in London in order to set up a project organization for the global platform. Internally, the project was called "Alt Click" an abbreviation for Alternative to Clicktivism, indicating that Amnesty searched for new ways to engage their online supporters and tie them closer to the organization. The project was inspired by trends on collective intelligence and social computing, and the idea was to mobilize digital supporters to analyze big amounts of data (such as social media data and/or satellite data) in order to help Amnesty researchers in tracking down human right abuses.

\subsection{Data Collection and Analysis}

We have been following the work of decoder project since its beginning in late 2014. We have conducted 17 interviews (and site visits) at the Amnesty section in Washington, at the International Secretariat in London, and at the Amnesty section in Stockholm, Sweden. We have also conducted Skype interviews with individuals directly involved or being consulted for the decoder project including the project leader, a moderator of the decoder project forum, and decoder supporters. The interviews gave us an understanding of the Amnesty context, the decoder project organization, as well as insights on the decoder supporter community. In addition to the interview data we also downloaded data from the decoder forum, followed online debates and accessed public evaluations of the different decoder projects. This allowed us to get an understanding of the organizing, and incentives of the digital supporters active on the decoder platform. We have also gained access to project documentation such as the project description, consultancy reports, and the technological specifications in developing the decoder micro tasks and the associated digital infrastructures.

Our preliminary data analysis followed principles of qualitative case research [30]. All interviews were taped, transcribed, imported into Atlas.ti (a qualitative analysis software), and coded. While our initial coding was "open" [31] later stages of the analysis was informed by institutional logics theory and our reading on digital platforms. The longitudinal character of the research, the transparency characterizing the decoder initiative, and the access to the internal organization allowed us to trace down the coexistence of two partly contrasting logics: the logic of the SMO - characterized by collective identity, deep knowledge and centralized control, and the digital platform logic emphasizing isolated action, personalization and entrepreneurial action.

\section{Results - The Decoder Case}

"[with the decoder project] were not just telling them [supporters], sign this petition because its important. We're telling them, be a researcher for a day. [...] it's a value proposition". (Decoder project leader, May 2016)

In this section we start by describing the preexisting logic of collective action at Amnesty (the SMO logic). We then describe the digital platform logic and how the logics were manifested in the decoder projects.

\subsection{The Logic of Collective Action at Amnesty}

While Amnesty had previously engaged digital supporters in mobilization activities with digital technology (especially through social media) [32] digital supporters had historically not been involved in the research or investigations of human rights violations. Rather, Amnesty was an expert organization that relied heavily on its "on-the-ground" researchers. Thus, the concept of including digital supporters in researching human right violations were 
unprecedented. The initial concerns of the formal organization were not just about risks but also related to the quality of evidence. The project leader elaborated: "...our researches are quite skeptical about contributions from people around the world. We typically work with people who have two PhD's and are very experienced in research and have solid contacts on the ground and spend a lot of time on these issues. They would be probably quite skeptical about data that is coming from 2,000 people from around the world." (Interview in NetPose podcast1).

Traditionally, Amnesty researchers would exert much influence on identifying political opportunity structures, writing reports on human right violations, and influence campaign work and design. While this structure favored a centralized approach to collective action, it also clearly separated the formal organization from its supporters. Supporters were expected to act on pre-designed campaigns, not engage in collecting data or collecting evidence of abuse. The organization had, in general, high expectations of the "altruistic" motives of their supporters. Supporters were conscience constituents in the sense that they contributed to the campaigns without standing to benefit from its success, acting primary on the basis of conscience and on the directions of Amnesty. More so, any selection of issues researched by the Amnesty researchers, as well as all supporter contributions, was expected to be indifferent to media trends. In our interviews, especially when discussing the potential of digital media, we often heard "we do not want to become populists" (field notes). In general, the collective action logic at Amnesty promoted selfless and unbiased commitment from its supporters, and accuracy and expertise from its researchers. The decoder project contrasted this operational procedure. This is not to say that the decoders didn't represent and share the values of the traditional organization. Rather, the contrasting elements rested in the very routine of inviting digital supporters to act on behalf of Amnesty without knowing about their incentives and, perhaps more significantly, knowing about the very outcome of their actions. The project leader elaborated: "It is more a theory of change that we're giving people. [It's] like an exposition of a problem and saying, you can be part of the solution. If we have this much data, then we can, maybe, solve the problem" (Decoder project leader, April 2018).

\subsection{The Decoder Platform and the Co-existence of Logics}

1https://medium.com/@drewwilson/finding-alternativesto-clicktivism-316f16670787\#.x5p8utvod
Although multi-year funding was secured, the decoder project struggled initially to find a home within the structures of the organization. There was ambiguity as to what would be micro-tasked and the quality of the data. Initially, some believed that the new project involved new evidence collection such as civilians taking images at protests. Others believed that the initiative included analyzing existing data that Amnesty already had or that Amnesty researchers would collect. The project leader elaborated: 'I was on a mission and thought of myself as an ambassador, but yeah [initially] people didn't understand the project."

Many factors contributed to the uncertainties; the newness of micro-tasking research activities, and the confusion of what crowd sourced data would be, its quality and how it could be used. Perhaps the most concerting element was how Amnesty would create the platform and protocols to invite and engage peripheral digital supporters in research, a core function of the professional organization. Despite the initial ambiguity the organization had high expectations on the project. In a 2015 press release Amnesty communicated: "This is an initiative with the potential to fundamentally transform the way we conduct human rights work."

In late 2015, Amnesty recruited an external project leader who launched the platform development process. As a first action, she engaged a non-profit organization with expertise in developing technologies for NGOs, in order to evaluate platform alternatives for the decoder initiative. They settled on focusing on so called micro-task platforms, a technology that would split a large job into smaller tasks and distribute them over the internet, to a crowd of people. The project leader commented: "...it is important for us to work with open source and almost off-the-shelf-so that we can potentially work with others [software developers]. The platform choice will be critical"

The project leader pushed an open "request for proposals" on developing a micro-tasking minimum viable product platform (MVP platform). In the request, it was stated that Amnesty wanted the pilot to "unlock data [...] test microtasking as new way to engage our supporters and members in meaningful ways [...] test microtasking as research tool, in particular test the potential to support Amnesty analyze data that would otherwise be time-consuming to process or impossible to access". Thus, one of the key features of the platform would be to structure unstructured data through microtasks.

Amnesty received 8 different suggestions, and in the spring of 2016, they moved forward and develop the first pilot platform. To demonstrate the decoder potential internally, the first pilot was about decoding previous Amnesty campaigns (so called urgent 
actions). Over eight weeks 8000 digital supporters helped out with decoding and verify 2,443 urgent actions and identify trends in terms of where (geographically) Amnesty is most active, where violations have happened and where campaigning had been most effective. The pilot was considered a success and demonstrated the potential of the platform for the internal organization. The organization has, since then, with the help and support of Amnesty's research group launched three decoder projects "decode Darfur", "decode Oil Spills" and the "Troll patrol" project.

4.2.1. The Decode Darfur Project. The decode Darfur was the first decoder project that was connected to ongoing research with an "existing advocacy strategy" at Amnesty.

In early 2016 Amnesty researchers had published "...credible evidence that countless villages in Darfur have been attacked by the Sudanese government and its allied militias". The decode Darfur project was designed based on this report, hence the aim and scope of the project was relatively straight forward, and decoders were provided with a rich narrative to understand the project. The project aimed to identify and map satellite images of Darfur to identify remote villages and signs of destruction. The project was a success, it scaled rapidly and engaged more than 28,600 digital volunteers from 147 countries. They completed 1,146,602 micro-tasks over a time period of seven weeks and decoded over 326,000 square kilometers.

With the Darfur project the decoder platform was expanded to include a discussion forum aimed to support new decoders. This was a space where decoders could interact with the project leader, moderators and occasionally Amnesty researchers. Moderators and the project leader were very active in this space, motivating actors to interact and expose any concern. Amnesty had expected supporters to solve micro-tasks in isolation. However, the forum motivated actors to interact and collaborate. For example, decoders could "flag" tasks that they were unsure of (such as identifying a fire) and ask others to collaborate and solve the task. Below is an example from such a collaborative interaction (coding of a satellite image)

Decoder Y: Publishes (and flag) the image below:

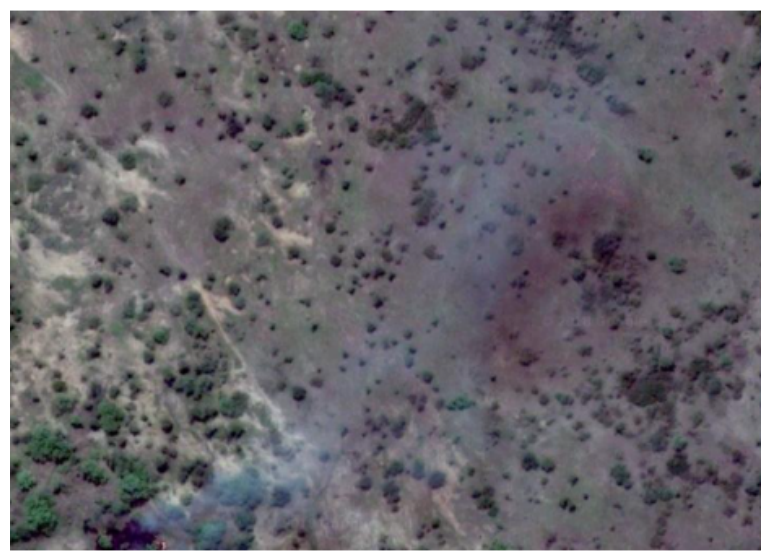

Decoder X: I'd love to look at the tile below this one... is it a grass fire or one tukul that is burning? You can see the actual burning here. I've spotted some tasks with similar terrain with smoke (I think).

Decoder Z: Well spotted

Essentially, the decoder forum created a limited space for collaboration, leveraged by the platform. "I follow many of the discussion threads. It's a great way of learning and improving my effectiveness at the tasks, as well as getting some human interaction :) It's also a good place to take breaks." (Decoder interview, May 2018).

For the professional cadre at Amnesty the decode Darfur project was an eye-opener in terms of the highquality masses of data produced by the community. In the Decoder discussion forum, moderators received questions from the decoders on what the Darfur data is being used for? The project leader commented: "As for Decode Darfur, we have analysed the data from Decoders but we want to go even a bit further. We realized that the data collected is a gold mine and can be used in conjunction with cutting edge artificial intelligence to map not only Darfur but the whole of Sudan and other areas in Africa. So, partnering with artificial intelligence researchers from University College London, we are training an artificial intelligence algorithm using the large amount of data offered by the Decoders"

The initial expectations were that the data from the decoders would be a help for ongoing research, few had anticipated the potential of the data for machine learning. More so, the extracted data from the project was used by Amnesty researcher in their reporting's.

The decode Darfur project was followed by a project on identifying Oil Spills in the Niger delta, Nigeria. The project was built on similar premises as the Darfur project, and linked to ongoing research. In 
2018 however, Amnesty launched a new decoder project called the "Troll Patrol". This project was significantly different from the two previous projects, particularly because it required more from the decoders and was more advanced in terms of the micro-tasks.

4.2.2. The Troll Patrol project. The troll patrol project was about stopping online violence and abuse on Twitter, it was directed towards women and marginalized groups and it was based on one of Amnesty's core values related to the freedom of expression. The project micro-tasked Tweets (see Figure 1), and decoders were asked to code if the Tweet were abusive, problematic or not problematic. Similar to the Decode Darfur project the Troll Patrol project also aimed at experimenting with machine learning and algorithms for detecting abuse. The project leader commented: "In the long term, we also want to use this data to experiment with developing algorithms that detect abuse. We do all this to put more pressure on Twitter itself to improve their response to online abuse. They are not disclosing information about numbers and nature of reports of abuse. They are not taking the issue seriously so we need to show them just how serious it is".

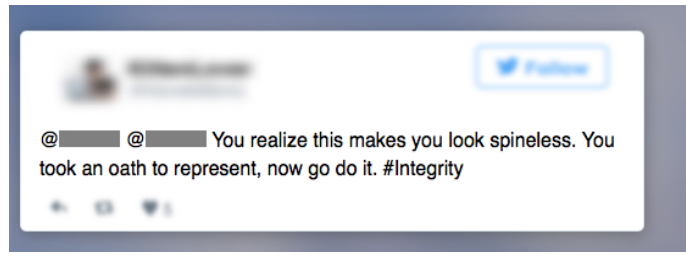

\section{Does the tweet contain problematic or abusive content?}

Please look at the tweet and let us know if it contains problematic or abusive content.

\begin{tabular}{|l|l|}
\hline No & 1 \\
\hline Problematic (1) & 2 \\
\hline Abusive (1) & 3 \\
\hline
\end{tabular}

Figure 1. Example of micro-task from the Troll Patrol project.

Decoding tweets was a more complicated task than in previous projects mostly because there were many "borderline" cases that could be interpreted in different ways by the decoders. This difficulty revealed the heterogeneity of the decoders, for example, what was found to be abusive to some, were not coded as abusive to others. As described by one of the decoders in one of our email conversations: "... [it is difficult with] the lack of context in the tweet (but I perfectly understand the reason for this) [and] trying to keep one's focus (on abuse targeted at women) when there is distracting/triggering content, e.g. abuse relating to other groups of people" (decoder email interview, May 2018). This ambiguity, combined with personal experiences of online abuse triggered decoders to engage more in the online forum. In the forum, decoders discussed difficult tasks and flagged Tweets that they were unsure about. Moderators were active in helping out and endorsed all action and tasks completed. Still the Troll Patrol project suffered from not having as strict boundaries, clear goal, and context as the previous projects, creating ambiguity amongst the decoders.

Due to the active forum discussions, decoders started to engage in (envisioned) entrepreneurial action. For example, decoders took it onto themselves to expose Tweets that they had found particularly offensive, they also engaged in sharing personal experiences of online abuse. Such actions had nothing to do with the micro-tasks and was rather surprising to Amnesty. One of the forum moderators commented: "... last week we had somebody posting who was posting about some personal problems[...]And as moderators, we were talking and like, how do we respond to this? And I think the consensus we came up to was like, you know, reply and express that we're there and people are listening, but not to necessarily promote that kind of conversation on the forum because I guess technically, that's not what it's there for". More so, decoders increasingly asked Amnesty to provide additional incentives for participation. One very salient example of this was the request on certificates of completed micro-tasks and proof of volunteer hours spent on the decoding initiative, as illustrated by these quotes from the forum: "Hello, I recently joined this site and I would really appreciate it if you could send me a certificate for volunteering" and "I would like to have the decode certificate as a new member." While, the request for certificates was relatively easily resolved (by extracting data on each decoders time spent in the project) the request signaled a step away from altruistic and collective engagement towards individual entrepreneurial action. More so, the individual action of decoders pointed at increased "individualization" [7] by the exposure of personal action frames, by sharing for example, personal experiences of online abuse. Still, such action was restricted to the narrow domains of the digital platform. In this way, and particularly through the responsiveness of the moderators and the project 
leader, entrepreneurial action was envisioned by the decoders but remained within the boundaries of the project. Decoders that suggested improvements or adjustments in the project received rapid attention by the moderators. For example:

Decoder April 6" 10.55 PM: "I'm worried about the fact that I can see the first and last names of all the people on this thread. I think this project has the potential for retaliation, and I don't want to see people get harassed just for their participation [...] Sorry to be such a downer on my first post, but security is a big concern for me".

Moderator April 6 ${ }^{\text {th }}$ 11.01 PM: Hi there, thanks so much for flagging this! We are looking into it now and I will get back to you with an update asap

Moderator, April $7^{\text {th }} \mathbf{1 0 . 1 9}$ am: [...] We have now disabled all names showing here on the forum. Thanks again for pointing this out, really helpful feedback.

Given the more complex nature of the micro-tasks in the Troll Patrol, Amnesty invited the decoders to meet with their researchers and experts that had been engaged in designing the project in online Q\&A sessions. These online sessions were salient examples of collaborative relationships between the traditional logic of SMO and the platform logic. In such sessions researchers and experts were interviewed/asked about particular tasks, and about how the data produced by the decoder community would help them in their research. Collaborative relationships between the research group and the decoder initiative were mostly evident in addressing strategic and high-risk issues, such as the risk of decoders solving micro-tasks in the wrong way.

\section{Discussion and Implications - The Co- existence of Logics}

For SMOs, the choice and development of new ways to engage people include many risks, since what motivates one action repertoire suitable for a particular aim, may conflict with the action aimed achieving another [12]. Although extant research recognizes this possibility, little is known about how digital platforms for collective action, such as the decoder initiative, might coexist with the traditional SMO logic.

As extant research would predict, the SMO logic for mobilization and research at Amnesty was characterized by expertise and control. Mobilization of members and supporters was following upon the field reports by the trusted researchers. Members responded to the calls of the organization in terms of how and when to take action. Action, in turn, was directed towards a shared and clear goal. Supporters responded to predesigned issues and engaged in them with altruistic motives.

Researchers studying digital technology such as digital platforms in collective action have described a fundamentally different logic from that of traditional SMOs. The logic rests on rapid scaling of heterogeneous groups for short term engagement and room for individual agency that includes entrepreneurial activities. We certainly found elements of this platform logic in the decoder initiative. Heterogeneous actors connected only through the digital platform, and acted without necessarily sharing the same values of the projects. Despite this, decoders expressed a sense of collectiveness. A decoder elaborated: "[It is the] sense of amazement at the technology involved, which allows people from all over the world to come together to make a contribution" (Decoder, May 2018).

The digital platform, and the highly moderated forum created a space for envisioned entrepreneurial action within a very narrow scope. Notably, there was not just individual action but also ongoing collaboration among digital supporters and representatives from the professional cadre. Table 1 provides an illustrative overview of the two logics.

\section{Table 1. Overview of Logic}

\begin{tabular}{|l|l|}
\hline The SMO Logic & The Platform Logic \\
\hline $\begin{array}{l}\text { Research rest on deep } \\
\text { knowledge (expertise) } \\
\text { and on-the-ground } \\
\text { presence. }\end{array}$ & $\begin{array}{l}\text { Research rest on crowd } \\
\text { intelligence through } \\
\text { micro-tasking. }\end{array}$ \\
\hline Altruistic Motives & $\begin{array}{l}\text { Entrepreneurial Motives } \\
\text { and professional } \\
\text { "certificate rewards" }\end{array}$ \\
\hline Expert knowledge & $\begin{array}{l}\text { Big data through human } \\
\text { microtasking of } \\
\text { unstructured data }\end{array}$ \\
\hline Knowledge co-creation & $\begin{array}{l}\text { Data co-creation through } \\
\text { collaboration }\end{array}$ \\
\hline $\begin{array}{l}\text { Overarching aim to } \\
\text { "report on human rights } \\
\text { abuses" }\end{array}$ & $\begin{array}{l}\text { Overarching aim to } \\
\text { generate structured data } \\
\text { and develop algorithms } \\
\text { for tracking human right } \\
\text { abuses }\end{array}$ \\
\hline
\end{tabular}

Initially the two logics co-existed in the way of being largely decoupled. The SMO logic were firmly rooted among the professional cadre of Amnesty. The platform logic was manifested in the design of the decoder initiative. The initial linkages between the two logics appeared to be primarily through key individuals at Amnesty (forum moderators, researchers and the project leader) who provided the support of the decoder initiative and had the foresight to see how the 
two logics could eventually benefit each other. For example, the project leader and the online moderators understood that the "Troll patrol" was complex in terms its relative newness, and lack of context. These actors rapidly added information to the decoders by inviting research experts in live sessions and Q\&A on the platform. In this way, as suggested by Huang et al. [37] the meaning making process amongst the decoders became interwoven in the digital platform logic.

As data poured in, the initiative gained external and internal visibility. The initial decoupling of the two logics was changing as to what we might consider partial blending in which both logics with different belief systems coexist and depend for each other's inputs and outputs. The decoder projects arose from ongoing research and campaign work at Amnesty. Hence, the groundwork that the research function at Amnesty had done was instrumental for the success of decoder projects. Data output of the decoder project built new evidence and allowed development of algorithms capabilities for tracking human right abuses. Hence, the output could be linked to the overarching aim of traditional logic to report on human rights abuses. While the decoder initiative is still in an early stage, there are some evidence that the decoder initiative linked the traditional SMO logic and the platform logic at the organization. What we do not see include compromising and logic synthesis as reported within the iOS app developers [13].

Yet, what remains is how the initiative will leverage its digital scaling and engage an even broader public globally. The more complex and challenging Troll Patrol project has not (yet) reached the numbers of digital supporters comparable to previous public projects. The Troll Patrol microtasks appeared to lack context, that is, decoders never had a sense of "getting the whole picture" and hence had difficulties of envisioning the project goal. This ambiguity might also partly explain the entrepreneurial action related to the project. That is, decoders took it onto themselves to interpret and in some cases challenge the project design. For example, decoders asked Amnesty to include new categories in coding the Tweets such as "positive and inspiring" in addition to "abusive".

One other major challenge is related to how SMOs can navigate the scaling of expectations [33] that comes with increased heterogeneity. For example, contrary to Amnesty's ambition to act for those that are outside of the media spotlight, all decoder projects were aligned with issues that were trending in society. While this helped to premediate and scale the intensity of the projects it increases the vulnerability of the organization because it challenges some of its core values. Another challenge with the platform logic is how SMOs, such as Amnesty can afford to build data science capability. Tech competence is very expensive and has not been even close to the core of Amnesty work. It might suggest a move towards what Hensby et al [11] described as "protest business" organizations. SMOs like Amnesty might need to become more business-like in order to retain highly sought-after data science skills. More so, the decoders requests for certificates pointed in a direction of individualization and profession rather than traditional political action with altruistic motives.

As noted above, the platform logic coexisted with the existing SMO logic. The logics were blended only in instances related to action and behavior (i.e microtasks as a way to produce research data) not in terms of their respective belief systems. We believe that such coexistence and "partial blending" was possible because of the digital platform. It leveraged a layered sociotechnical system on which different actors could operate. Researchers could continue to operate at the core while digital supporters (decoders) would remain in the periphery. More so, we also believe that the active and instant moderation of the community helped to leverage the "partial blending" of logics. We never identified signs of synthesis of value systems, simply because there was no space for negotiations or interactions of the fundamental premises of the formal organization or the decoder project. Hence, the pluralism of logics may have similarities to what Berente and Yoo [35] reported in terms of "loose coupling" although the specific forms of loose coupling that were manifested will have to wait for deeper analysis.

Last, we found that the digital scaling of political action work emerged associated processes of datification [29]. Datification is commonly viewed in terms of "put[ing a phenomenon] in a quantified format so it can be tabulated and analyzed" [36 p. 29]. In the decoder initiative the use of data for development of algorithms evolved during the decoder project. Similar to what was found by Huang et al [37] the project leader was able to "project novel value" without making any major changes in the core technology.

In conclusion, our analysis is preliminary and so are our findings. The study offers glimpses into one incumbent organization's journey to a platform economy and the experimentation and innovation around digital platforms. The Decoder initiative can shed light to how new crowd-based innovations gain legitimacy and instill collaborative relationships with highly established "expert" functions in a large hierarchical global organization. 


\section{References}

[1] Yoo, Y., Henfridsson, O., \& Lyytinen, K. 2010. The New Organizing Logic of Digital Innovation: An Agenda for Information Systems Research. Information Systems Research, (21:4): 724-735.

[2] Nambisan, S., Lyytinen, K., Majchzak, A. \& Song, M 2017. Digital Innovation Management: Reinventing Innovation Management Research in a Digital World, MIS Quarterly, 41(10): 223-238.

[3] Gil de Zúñiga, Z., Jung, N., \& Valenzuela,S. 2012. Social media use for news and individuals' social capital, civic engagement and political participation. Journal of Computer-Mediated Communication, 17(3): 319-336.

[4] Treré, E. 2015. Reclaiming, proclaiming, and maintaining collective identity in the\# YoSoy132 movement in Mexico: an examination of digital frontstage and backstage activism through social media and instant messaging platforms. Information, Communication \& Society, 18(8): 901-915.

[5] Theocharis, Y., Lowe, W., van Deth, J. W., \& GarcíaAlbacete, G. 2015. Using Twitter to mobilize protest action: online mobilization patterns and action repertoires in the Occupy Wall Street, Indignados, and Aganaktismenoi movements. Information, Communication \& Society, 18(2): 202-220.

[6] Van Laer, J., and Van Aelst, P. 2010. Internet and Social Movement Action Repertoires, Information, Communication, \& Society, 13(8): 1146-1171.

[7] Bennett, W. L. \& Segerberg, A. 2012. Digital media and the personalization of collective action: Social technology and the organization of protests against the global economic crisis. Information, Communication \& Society, 14(6): 770799

[8] Chadwick, A., \& Dennis, J. 2016. Social media, professional media and mobilisation in contemporary Britain: Explaining the strengths and weaknesses of the Citizens Movement 38 Degrees. Political Studies, 65(1):42-60.

[9] Kavada, A. 2015. Creating the collective: social media, the Occupy Movement and its constitution as a collective actor. Information, Communication \& Society, 18(8): 872886.

[10] Klandermans, B. 1997 The Social Psychology of Protest, Blackwell Publishers, 1997, Oxford.

[11] Hensby, A., Sibthorpe, J., \& Driver, S. 2012. Resisting the 'protest business': Bureaucracy, post-bureaucracy and active membership in social movement organizations. Organization, 19(6): 809-823.
[12] Zald, M. N., \& Ash, R. 1966. Social movement organizations: Growth, decay and change. Social forces, 327341.

[13] Qiu, Y., Gopal, A., Hann, I-H. 2017. Logic Pluralism in Mobile Platform Ecosystems: A Study of Indie App Developers on the iOS App Store. Information Systems Research, 28(2): 225-249.

[14] de Reuver, M., Sorensen, C., \& Basole, R. 2017. The Digital Platform: A Research Agenda, Journal of Information Technology, 33(2):1-12.

[15] Tilson, D., Lyytinen, K., and Sørensen, C. 2010. Research Commentary - Digital Infrastructures: The Missing IS Research Agenda, Information Systems Research, 21(4):748-759.

[16] Tiwana, A., Konsynski, B., and Bush, A. A. 2010. Research Commentary -Platform Evolution: Coevolution of Platform Architecture, Governance, and Environmental Dynamics, Information Systems Research, 21(4): 675-687.

[17] Gerbaudo, P., \& Treré, E. 2015. In search of the 'we'of social media activism: introduction to the special issue on social media and protest identities Information, Communication \& Society, 18(8):865-871.

[18] Miranda, S. M., Young, A., \& Yetgin, E. 2016. Are social media emancipatory or hegemonic? Societal effects of mass media digitization. MIS Quarterly, 40(2): 303-329.

[19] Vaast, E., Safadi, H., Lapointe, L., \& Negoita, B. 2017. Social Media Affordances for Connective Action: An Examination of Microblogging use During the Gulf of Mexico Oil Spill. MIS Quarterly, 41(4): 1179-1205.

[20] Salge, C. A. D. L \& Karahanna, E. 2018. Protesting Corruption on Twitter: Is it a Bot or Is it a Person. Academy of Management Discoveries, 4(1): 32-49.

[21] Friedland R., \& Alford, R.R. 1991, Bringing Society Back In: Symbols, Practices, and Institutional Contradictions, In: W. W. Powell and P. J. DiMaggio, Eds., The New Institutionalism in Organizational Analysis, University of Chicago Press, Chicago, US.

[22] Thornton, P. H., \& Ocasio, W. 2008. Institutional logics. In R. Greenwood, C. Oliver, R. Suddaby \& K. SahlinAndersson (Eds.), The Sage handbook of organizational institutionalism, London: Sage.

[23] Thornton, P.H., Ocasio, W., Lounsbury, M. 2012. The Institutional Logics Perspective: A New Approach to Culture, Structure, and Process. Oxford University Press, Oxford, UK.

[24] Greenwood, R., \& Suddaby, R. 2006. Institutional entrepreneurship in mature fields: The big five accounting firms. Academy of Management Journal, 49(1): 27-48. 
[25] Pache, A. C., \& Santos, F. 2013. Inside the hybrid organization: Selective coupling as a response to competing institutional logics. Academy of Management Journal, 56(4): 972-1001.

[26] Ramus, T., Vaccaro, A., \& Brusoni, S. 2017. Institutional Complexity in Turbulent Times: Formalization, Collaboration, and the Emergence of Blended Logics, Academy of Management Journal, 60(4): 1253-1284.

[27] Reay, T. \& Hinings, C.R. 2009. Managing the Rivalry of Competing Institutional Logics. Organization Studies, 30(6): 629-652.

[28] Kaganer, E., Carmel, E., Hirscheim, R., \& Olsen, T. 2013. Managing the Human Cloud, MIT Sloan Management Review, 52(2): 23-32.

[29] Newell, S. \& Marabelli, M. 2015. Strategic Opportunities (and Challenges) of Algorithmic DecisionMaking: A Call for Action on the Long-Term Societal Effects of 'datification', Journal of Strategic Information Systems, 24(1): 3-14.

[30] Klein, H. K., \& Myers, M. D. 1999. A set of principles for conducting and evaluating interpretive field studies in information systems. MIS Quarterly, 23(1):67-93.

[31] Charmaz, K. 2011. Grounded theory methods in social justice research. In N. K. Denzin, \& Y. S Lincoln (Eds.), The SAGE handbook of qualitative research, (359-380). Thousand Oaks, CA: SAGE.

[32] Selander, L., \& Jarvenpaa, S. L. 2016. Digital Action Repertoires and Transforming a Social Movement Organization. MIS Quarterly, 40(2): 331-352.

[33] Papacharissi 2015. Affective publics and structures of storytelling: sentiment, events and mediality", Information, Communication \& Society 19(3): 307-324.

[34] Powell, W.W. 2017. A Sociologist Looks at Crowds: Innovation or Invention? Strategic Organization, 15(2):289297.

[35] Berente, N. \& Yoo, Y. 2012. Institutional Contradictions and Loose Coupling: Postimplementation of NASA's Enterprise Information Systems, Information System Research, 23(2): 376-396.

[36] Mayer-Schonberger, V., Cukier, K., 2013. Big Data: A Revolution That Will Transform How We Live, Work and Think. John Murray Publishers, London, UK.

[37] Huang, J., Henfridsson, O., Liu, M. J., \& Newell, S. (2017). Growing on Steroids: Rapidly Scaling the user base of digital ventures through digital innovation. MIS Quarterly, 41(1):301-314

[38] Aaltonen, A. \& Tempini, N. 2014. Everything Counts in Large Amounts: A Critical Realist Case Study on Data-Based
Production, Journal of Information Technology, 29:1: 97110.

[39] Lehrer, C., Wieneke, A., Brocke, J.V., Jung, R., \&Seidel, S. 2018. How Big Data Analytics Enables Service Innovation: Materiality, Affordance, and the Individualization of Service. Journal of Management Information Systems, 35(2): 424-460.

[40] Gunther, W.A., Mehrizi, M.H.R., Huysman, M., \& Feldberg, F. 2017. Debating big data: A literature review on realizing value from big data. Journal of Strategic Information Systems, 26(3): 191-2009.

[41] Lyytinen, K \& Gover, V. 2017. Management Misinformation Systems: A Time to Revisit, Journal of Association for Information Systems, 18(3): 206-230. 